
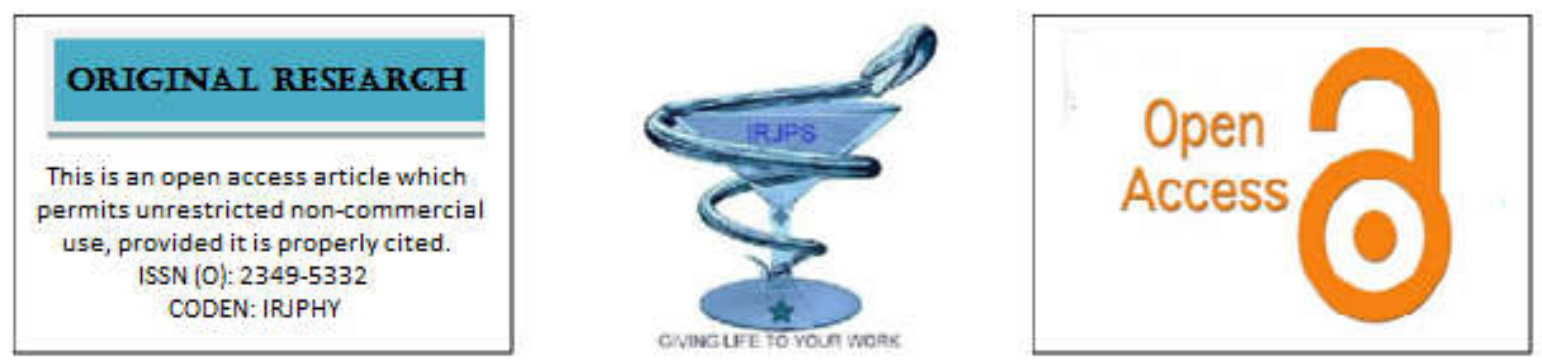

\title{
DEPRESSION AMONG PATIENTS VISITING REHABILITATION OUTCLINICS AT ROYAL MEDICAL SERVICES, JORDAN
}

\author{
Deifallah M. Alsharari*, Zeyad S. Bataineh, Osama R. Atoom, Rafat A. Alhabashneh, Mohammad T. \\ Alkhazaleh, Maxim A. Obaisat \\ Royal Medical Services, Jordan
}

Submitted on: 21.03.19;

Revised on: 29.03.19;

Accepted on: 05.04.19

\begin{abstract}
:
Depression is considered a real problem among patients with chronic diseases and usually ends with a variety of problems with psychological, social, and medical context. The prime objective of the present study is to assess the level of depression among patients visiting rehabilitation out-clinics at Royal Medical Services, Jordan.

Study design: A cross sectional study design was employed to collect data from patients. A total of 299 individuals who visited rehabilitation out-clinics at Royal Medical Services, Jordan, were included in this study.

Sampling technique: Rehabilitation out-clinics were randomly selected and patients who accepted to participate signed a consent form.

Study instrument: Depression was measured using AARON TEMKIN BECK scale for depression. According to this scale, there is no depression, mild depression, moderate depression, or severe depression. There was another part concerning with personal data including: age and gender.

Statistical analysis: Following data collection, the data was entered into SPSS version 21 for statistical analysis. Descriptive analysis was used to describe data in terms of means, standard deviations, frequencies, and percentages. Study findings: The main findings of the present study were: the prevalence of depression was $13.40 \%$. The mean age of study participants was $56.13 \pm 17.98$ years, and the study included 157 females $(52.7 \%)$.

Conclusion: The present study showed that patients with chronic diseases have a prevalence of depression about $13 \%$.

KEYWORDS: Depression, chronic disease, instrument, rehabilitation, prevalence.

Corresponding Author: Deifallah M. Alsharari E-mail: alsharari76@yahoo.com

Indian Research Journal of Pharmacy and Science; 20(2019)1791-1795; Journal Home Page: https://www.irjps.in DOI: $10.21276 /$ irjps.2019.6.1.4
\end{abstract}




\section{INTRODUCTION:}

Depression is considered as a psychiatric condition with prevalence among patients with chronic diseases including cancer $^{1}$.The general prevalence of depression in patients with chronic diseases has been estimated to range from $8-24 \%{ }^{2}$. Other studies suggested higher prevalence that may reach $38 \%{ }^{3}$. The prevalence of depression in general population has been established to be as $7 \%{ }^{4}$.

From economic point of view, depression is considered a costly mental health problem that is encountered in health settings ${ }^{5}$. The prevalence of major depressive disorder is about 5-13\% among patients examined in primary care settings ${ }^{6}, \quad 7$. However, what makes the problem difficult is that the occurrence of depressive disorders is underdiagnosed and under-treated ${ }^{8}$.According to the study of Wells et al. ${ }^{9}$, poor diagnosis and treatment of depression is the reason for the economic burden of depression. Furthermore, $50-60 \%$ of patients with depression are not well diagnosed ${ }^{10}$.

It has been shown that depression is more likely to affect young people, female patients,single, divorced and separated patients, in addition to those with serious diseases, or those with previous history of depression $^{11,}{ }^{12}$. Risk factors for developing depression include smoking and overweight, no regular exercise, and having high blood pressure and/or diabetes, and having angina ${ }^{13}$. Among patients with major depression who had cancer, the rates of depression ranged from $23-60 \%{ }^{12}$.

The prime objective of the present study is to assess the level of depression among patients visiting rehabilitation out-clinics at Royal Medical Services, Jordan.

\section{METHODS AND PATIENTS:}

Study design: A cross sectional study design was employed to collect data from patients.

Study population: Targeted population included patients who visitedrehabilitation out-clinics at Royal Medical Services, Jordan.

Study sample: A total of 299 individuals who visited rehabilitation out-clinics at Royal Medical Services, Jordan, were included in this study.

Sampling technique: Rehabilitationout-clinics were randomly selected and patients who accepted to participate signed a consent form. All patients were voluntary participated in this study and their data were handled confidentially for research purposes only.

Study instrument: Depression was measured using AARON TEMKIN BECK scale for depression. According to this scale, there is no depression, mild depression, or severe depression. There was another part concerning with personal data including: age and gender. Depression scale in its Arabic language was used.

Statistical analysis: Following data collection, the data was entered into SPSS version 21 for statistical analysis. Descriptive analysis was used to describe data in terms of means, standard deviations, frequencies, and percentages.

\section{RESULTS:}

\section{General characteristics of participants}

As shown in table 1, the mean age of study participants is $56.13 \pm 17.98$ years. Males were slightly 
less than females. Prevalence of depression among

patients was $13.40 \%$.

Table 1: General characteristics of participants

\begin{tabular}{|c|c|}
\hline Variable & Description \\
\hline Age (M \pm SD) years & $\mathbf{5 6 . 1 3} \pm 17.98$ \\
\hline Gender (N, \%): & $142(47.5 \%)$ \\
Male & $157(52.5 \%)$ \\
Female & \\
\hline Depression scale (N, \%): & $259(86.60 \%)$ \\
Depression & $\mathbf{4 0}(\mathbf{1 3 . 4 0 \% )}$ \\
No depression &
\end{tabular}

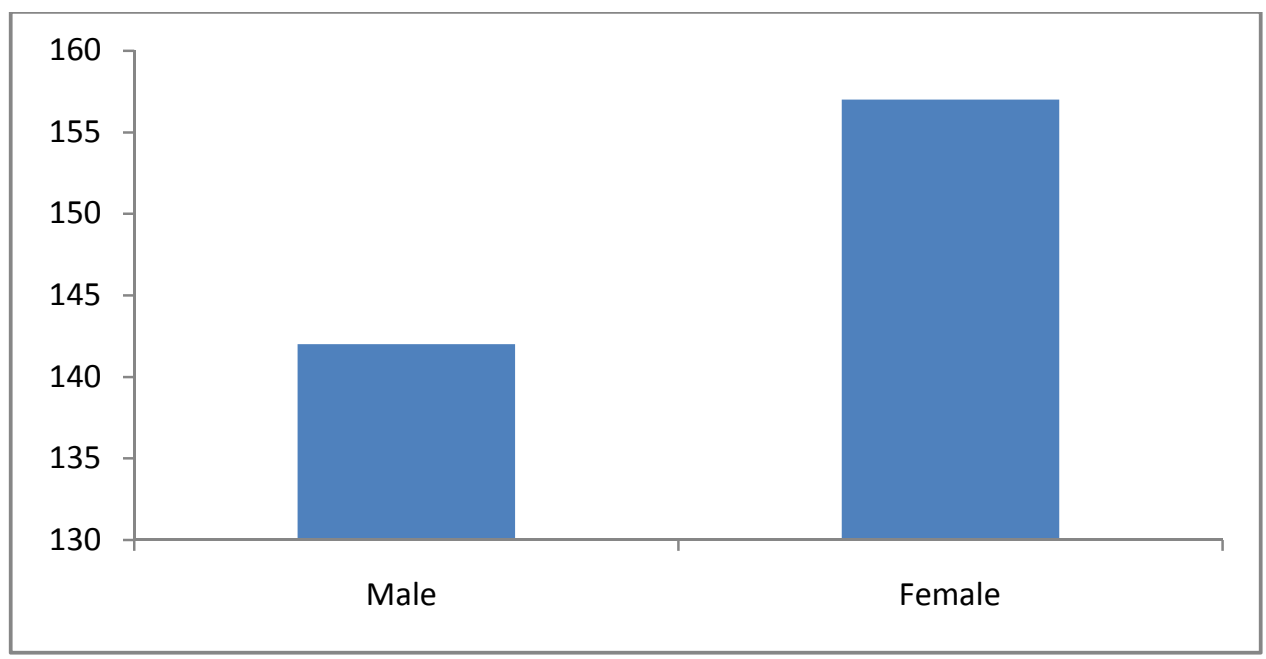

Figure 1: Frequency of gender of study participants

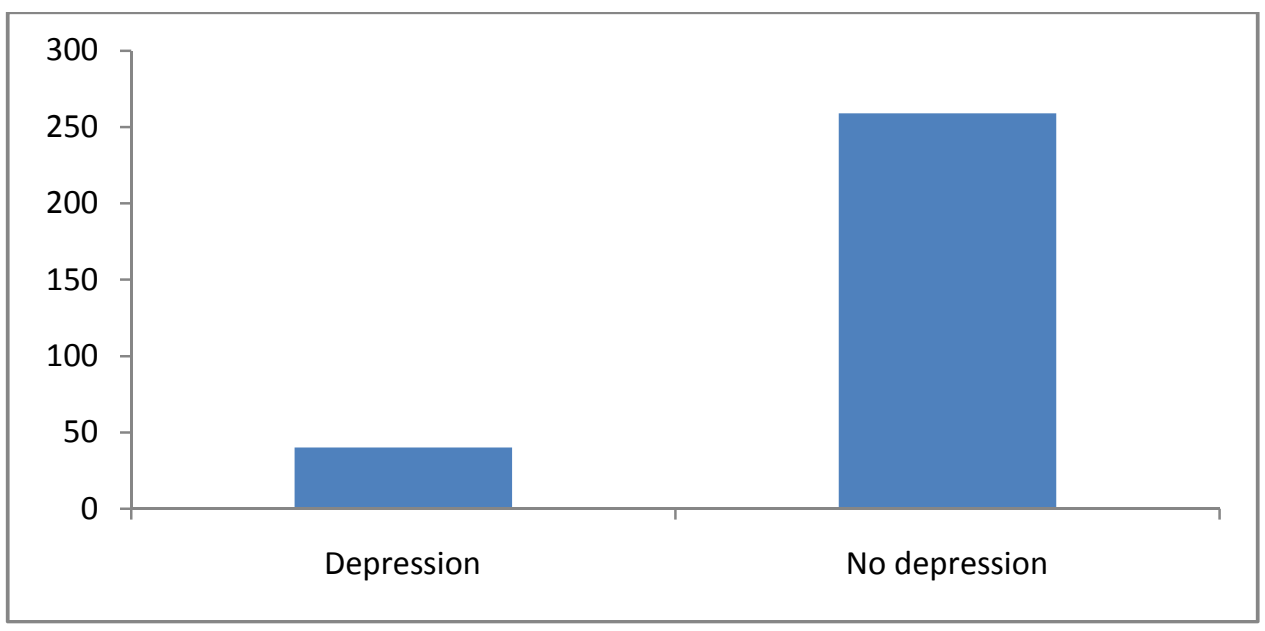

Figure 2: Depression status among study participants 


\section{DISCUSSION:}

The present study was conducted to determine the level of depression among patients visiting rehabilitation out-clinics at Royal Medical Services, Jordan. The findings of the present study showed that a total of 40 patients $(13.40 \%)$ were found to have depression. Patients with chronic diseases usually develop depression. Previous studies have reported a prevalence of depression among patients with chronic diseases to range from $8-24 \%{ }^{2}$. Other studies reported that prevalence could reach higher degree of depression $(38 \%)^{3}$. It seems that there is a tendency to develop depression among general population as reported by the study of Kessler ${ }^{4}$ who reported about $7 \%$ of general population developed depression. The level of depression in our study is within the limits reported in literature. Furthermore, we think that the prevalence of depression in our study is relatively

\section{REFERENCES:}

1- Brent T. Mausbach,Scott A. Irwin. Depression and Healthcare Service Utilization in Patients with Cancer. Psychooncology, 2017, 26(8): 1133-1139. doi:10.1002/pon.4133.

2- Krebber AM, Buffart LM, Kleijn G, et al. Prevalence of depression in cancer patients: a metaanalysis of diagnostic interviews and self-report instruments. Psychooncology, 2014; 23:121-130.

3- Massie MJ. Prevalence of depression in patients with cancer. J Natl Cancer InstMonogr. 2004;32:57-71. low and this can be explained by taking into consideration two issues. The first issue is that the mean age of the participants in this study is $56.13 \pm 17.98$ years. Usually, young people are more likely to develop depression. The second issue is that the frequency of males and female were similar. As previously mentioned, females are more likely to develop depression. According to this context, age and gender in this study did not participate effectively in developing depression. This is consistent with previous studies ${ }^{11,12}$.

\section{CONCLUSION:}

The present study showed that patients with chronic diseases have a prevalence of depression about $13 \%$. The prevalence of this depression is considered relatively low because the mean age of participants is not young, and the females were not predominant.

4- Kessler RC, Petukhova M, Sampson NA, Zaslavsky AM, Wittchen HU. Twelvemonth and lifetimeprevalence and lifetime morbid risk of anxiety and mood disorders in the United States. Int $\mathrm{J}$ Methods Psychiatr Res., 2012; 21:169-184.

5- Katon W, Schulberg H. Epidemiology of depression in primary care. Gen Hosp Psychiatry, 1992; 14: 237-247.

6- Schulberg HC, Saul M, McClelland M, Ganguli M, Christy W, Frank R. Assessing depression in primary medical and psychiatric practices. Arch Gen Psychiatry, 1985; 42: 1164-1170. 
7- Coyne JC, Fechner-Bates S, Schwenk TL. Prevalence, nature, and comorbidity of depressive disorders in primary care. Gen Hosp Psychiatry 1994; 16: 267-276.

8- Amin A. Gadit. Out-of-Pocket Expenditure for Depression Among Patients Attending Private Community Psychiatric Clinics in Pakistan. J Ment Health Policy Econ, 2004, 7, 23-28.

9- Wells H. Detection of depressive disorder for patients receiving prepaidor fee-forservice care. JAMA, 1989; 262: 3298-3302.

10- Greenberg PE, Stiglin LE, Finkelstein SN, Berndt ER. The economicburden of depression in 1990. J Clin Psychiatry, 1993; 54: 405-418.
11- Weissman MM, Bland RC, Canino GJ, Faravelli C, Greenwald S, Hwu HG, et al. Cross-national epidemiology of major depression and bipolar disorder. J Am Med Assoc, 1996, 276:293-299.

12- Wageeh A.N. Hassan, Ahmed M.M. Hany, Alaa M. Darwish,KhaledA. Mohammed, Hosam E. Khalifa, Ahmed A. AbdelRahman. Risk factors for depressive disorders among patients attendingoutpatient clinics of Assiut University Hospitals. Egyptian Journal of Psychiatry 2013, 34:10-18.

13- Wassertheil-Smoller S, Shumaker S, Ockene J, Talavera GA, Greenland P, Cochrane B, et al. Depression and cardiovascular sequelae in postmenopausal women. The Women's Health Initiative (WHI). Arch Intern Med., 2004;164:289298. 